\title{
Self Prepared Herbal Mouthwash Used As Pre-procedural Rinse in Reducing Dental Aerosol: A Substitute to Chemical Mouthrinse: A Clinico-Microbiological Study
}

\author{
Research Article
}

\section{Chinnu Mary Varghese ${ }^{1}$, Vidushi Sheokand ${ }^{2 *}$, Amit Bhardwaj ${ }^{3}$, Harender Sehrawat ${ }^{1}$, Ridhima Uppal ${ }^{1}$, Kevin Raj ${ }^{1}$}

1. PG Scholar, 2. Associate Professor, 3. Professor \& Head of the Department, Department of Periodontology, Faculty of Dental Sciences, SGT University, Gurugram.

\begin{abstract}
Aim:To evaluate and compare the efficacy of pre-procedural mouth rinses in reducing microbial content of aerosol product during ultrasonic-scaling procedures by viable bacterial count.Materials And Methods:5 patients were assigned in each group: A- Neem, B -CHX, C-Triphala, D - Control Group.In Group A, B, C -Patient were asked to rinse their mouth with $10 \mathrm{ml}$ mouthwash for 30 seconds before SRP, of which A and C are self- prepared herbal mouthwashes i.e Triphala and Neem. Aerosol will be collected, cultured and incubated on blood agar plates at specified sites from operator. CFU will be counted and result will be assessed statistically. Conclusion: The study suggests that $10 \mathrm{ml}$ of Neem Mouth rinse when used 10 minutes prior to ultrasonic scaling is more potent in reducing the aerosol contamination as compared to the Triphala mouth rinse and commercially available $0.2 \%$ Chlorhexidine mouthrinse. Also the reduction in aerosol content was seen in Tray location when rinsed with CHX and aerosol reduction in Spitoon and Chest location while rinsing with Neem mouthrinse.
\end{abstract}

Key Words: Aerosols, Pre-procedural rinsing, Chlorhexidine, Herbal Mouthwashes, Colony forming units.

\section{Introduction}

The growth of infectious microorganisms within aerosols is identified as an important health risk linked with specific occupations.(1)Inspite of the efforts made to bring down these health hazards, they are inevitable in the work place by nature of the profession.(2) Most of the procedures carried out in the mouth, leads in the formation of aerosol and splatters which are usually mixed with bacteria, fungi, protozoa and even blood borne viruses.(3)The terms "aerosol and splatter" in dental enviornment were put forward by Micik in their pioneering work on aerobiology.(4)The microbial aerosol per concentrations in dental treatment rooms were related more with scaling procedures and to a minor extent with cavity preparation.(5)These aerosols may be inhaled into the lungs and reach the alveoli, or they may come in contact with the skin or mucous membranes thus result into infection. As suggested by Harrel and Molinari, the three levels of shield in the minimization of aerosols are the usage of:Personal Protective barrier such as masks,

* Corresponding Author:

Vidushi Sheokand

Associate Professor,

Department of Periodontology, Faculty of Dental

Sciences, SGT University,

Gurugram. India

Email Id: vidushi.sheokand@,gmail.com gloves and safety glasses, routine use of preprocedural rinse and use of high evacuation device.(6)

Chlorhexidine (CHX) is still considered the gold standard antimicrobial mouthmash because of its broad spectrum of the bacterial activity and prolonged substantivity (7) But it also has some side effects, notably tooth staining, taste alteration, supragingival calculus formation and, less commonly, desquamation of the oral mucosa.(8)On the other hand, herbal mouth rinses with their natural ingredients offer a safe and effective option that should be made use of in the most favourable way.(9) Chlorhexidine was compared with Triphala and Neem mouth wash as a preprocedural rinse.Triphala is a well known powdered preparation being used in Ayurveda and it consists of equal parts of the Embica Officinalis (Amalaki), Terminalia Chebula (Harritaki) and Terminalia (Vibhitaki). Neem exhibits anti- hyperglycemic, immunomodulatory, anti- inflammatory, anti-viral, anti-fungal, anti- bacterial activity .(10)

Hence, this study was aimed to evaluate the effectiveness of Chlorhexidine and Prepared Herbal mouth rinses on the reduction of aerosol contamination produced by ultrasonic scalerAIM:

To evaluate and compare the efficacy of preprocedural mouth rinses (Neem, Triphala, Chlorhexidine digluconate) in reducing microbial content of aerosol product during ultrasonic-scaling procedures by viable bacterial count. 
Chinnu Mary Varghese et.al., Herbal Mouth Rinse as an alternative to Chemical Mouth Rinse in Reducing Dental Aerosols

\section{Objectives}

- To evaluate bioaerosol production by counting colony forming units in test groups and control group at various sites from the patient undergoing Scaling and Root Planing Procedure.

- To compare and correlate the bioaerosol production in test groups and control group.

\section{Materials and Methods}

This study was conducted on patients who visited the Department of Periodontology in the SGT Dental College, Gurgaon.This study was done in collaboration with the Department of Ayurveda, Pharmacology and Microbiology, SGT University. Patients were informed about the study and their inclusion was purely voluntary.

\section{Study population}

Twenty patients with Chronic Periodontitis with the age range of 25-55 years were recruited in the study.

\section{Selection criteria}

\section{Table 1:Selection Criteria}

\begin{tabular}{l|l}
\multicolumn{1}{c|}{ Inclusion criteria } & \multicolumn{1}{c}{ Exclusion criteria } \\
$\begin{array}{l}\text { Participants having } \\
\text { minimum of } 20 \text { permanent } \\
\text { teeth }\end{array}$ & $\begin{array}{l}\text { The presence of any } \\
\text { systemic disease }\end{array}$ \\
$\begin{array}{l}\text { Participants diagnosed with } \\
\text { moderate-to-severe } \\
\text { periodontitis. }\end{array}$ & $\begin{array}{l}\text { Patients received antibiotics } \\
\text { or nonsteroidal anti- } \\
\text { inflammatory drugs in the } \\
\text { past 9-11 weeks. }\end{array}$ \\
$\begin{array}{l}\text { Systemically healthy } \\
\text { patients }\end{array}$ & $\begin{array}{l}\text { Oral prophylaxis within the } \\
\text { past 3 months }\end{array}$ \\
$\begin{array}{l}\text { Participants indicated for } \\
\text { full-mouth scaling in single } \\
\text { sitting. }\end{array}$ & $\begin{array}{l}\text { Pregnant and lactating } \\
\text { mothers } \\
\text { And Smokers }\end{array}$ \\
\hline
\end{tabular}

Table 2:Ingredients of mouth rinse

\begin{tabular}{l|l|l} 
Mouth rinse & $\begin{array}{l}\text { Trade } \\
\text { name }\end{array}$ & Ingredients \\
& & $\sqrt{ }$ Triphala powder, \\
& & $\sqrt{ }$ Mint oil, \\
& & $\sqrt{ }$ Aspartame powder \\
Triphala & - & $\sqrt{ }$ Stevia \\
& & $\sqrt{ }$ Methyl paraben \\
& & $\sqrt{ }$ Propyl paraben \\
& & $\sqrt{ }$ Chloroform \\
& & $\sqrt{ }$ Neem powder, \\
& & $\sqrt{ }$ Mint oil, \\
& & $\sqrt{ }$ Aspartame powder, \\
Neem & & $\sqrt{ }$ Stevia \\
& & $\sqrt{ }$ Methyl paraben \\
& & $\sqrt{ }$ Propyl paraben \\
& & $\sqrt{ }$ Ethanol \\
& & $\sqrt{ }$ CHX gluconate solution \\
Chlorhexidine & CLOHEX & I.P. diluted to CHX \\
& & gluconate $0.2 \%$ in aqueous \\
& & base \\
& &
\end{tabular}

\section{Preparation fo Mouth rinses}

Step 1: Preparation of Triphala And Neem Powder Triphala powder-The churna was prepared as per the procedure given in Ayurvedic department.All the given ingredients were powdered separately and then mixed together in specified proportions and to get uniformly blended churna .

Neem powder-The fresh neem leaves was sundried for 2 days until all the moisture from leaves get dried and crispy. Then the dried leaves were put into a blender and was grinded into a fine powder.

\section{Step 2: Extraction}

To $150 \mathrm{~g}$ of Triphala Powder, $500 \mathrm{ml}$ of distilled water and $1 \mathrm{ml}$ of chloroform was added.

To $150 \mathrm{~g}$ of Neem Powder, 50\% of water and $50 \%$ of ethanol was added i.e $250 \mathrm{ml}$ water and $250 \mathrm{ml}$ ethanol.

\section{Step 3: Filtration}

The mixture is then kept for 2 days for effective maceration and complete extraction.

- The macerated content was filtered through Muslin Cloth (Double Layered)

- The pre-filtered macerate was again processed through vaccum filter for the removal of particulate matter.

The obtained products were labeled as -
A. Neem extract
B. Triphala Extract

\section{Step 4: Evaporation Of Excessive Solvent}

In order to remove the excessive amount of solvent the extracts were subjected to evaporationon water bath for 60 degree celsius.

The obtained product was the concentrated extracts for formulation of mouth rinses.

Figure 1: Lab Formulated Mouth rinses
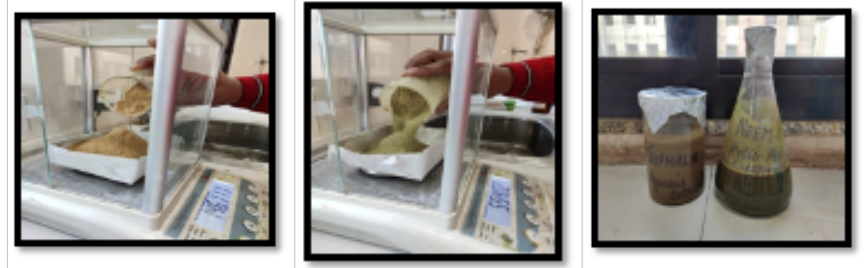

Step 1: Preparation of Powder
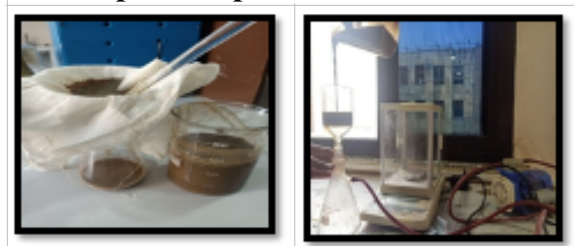

Step 2: Extraction

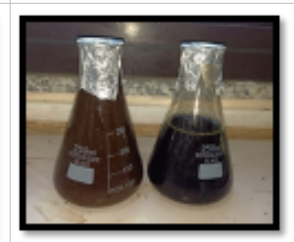

Step 3: Filtration
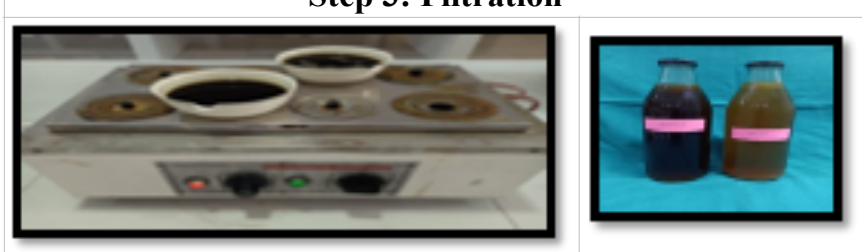

Step 4: Evaporation Of Excessive Solvent 


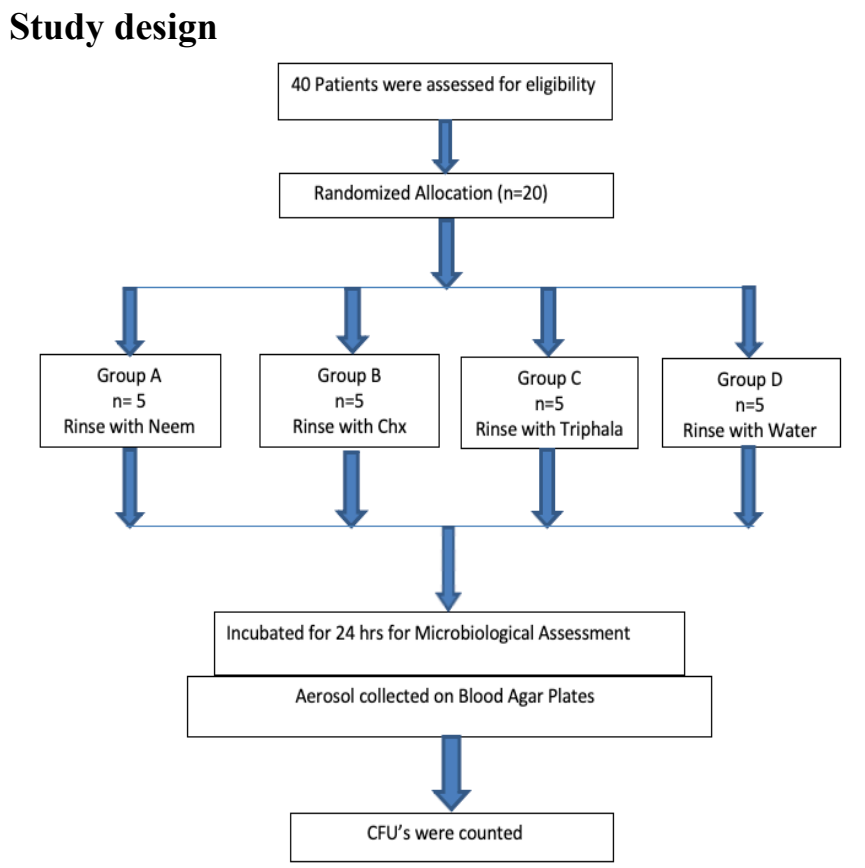

Clinical procedure

Mouth Rinsing

In Group A and C -Patients were asked to rinse their mouth with $10 \mathrm{ml}$ of prepared mouthwash and group B- with commercially available mouthwash chlorhexidine for 30 seconds before scaling and root planing procedure.

\section{Test Groups}

- Group A - Neem,

- Group B - Chlorhexidine digluconate

- Group C - Triphala

Control group

- Group D -Water

Figure 2: Blood Agar Plate Positioning

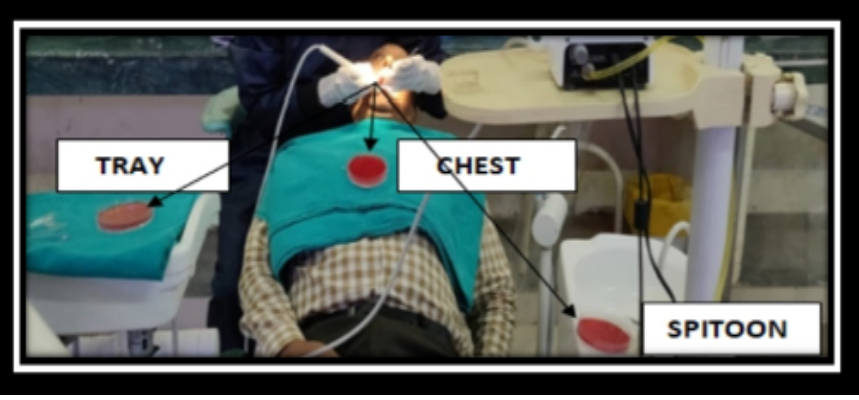

\section{Blood Agar Plate Positions}

- Reference Point: Patient's Mouth

- Plate 1- From Reference point to Chest - 12 inches

- Plate 2- From Reference point to Tray - 25 inches

- Plate 3-From Reference point to Spitoon - 30 inches

\section{Scaling and Root Planing Procedure}

The scaling is done for 10 minutes and the aerosols are collected on the the blood agar plates which is positioned at specific sites( i.e placed at Tray, Chest, Spitoon) from the reference point (i.e Patient's Mouth) during scaling and root planning procedures.

\section{Collection of Aerosols on Blood Agar plates}

Aerosol which was collected, cultured on blood agar plates at specified sites from reference point and then Colony forming Unit was counted.

\section{Microbial Analysis}

After collecting aerosols on Blood agar culture plate. The plates were placed in an incubator and incubated at 37 degree Celsius for $24 \mathrm{hrs}$.

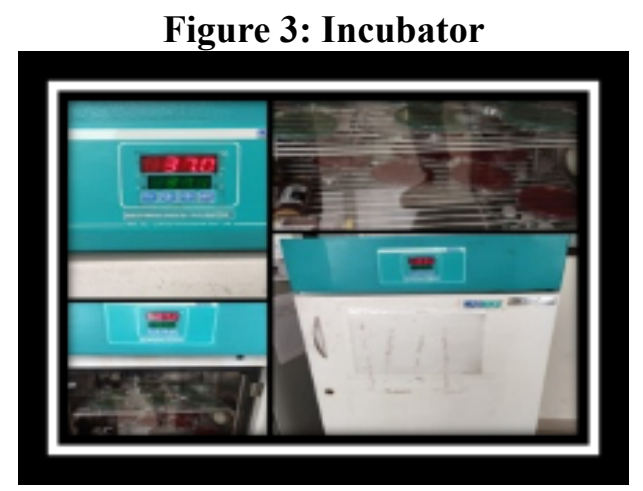

Figure 4: Microbial analysis of all the four groups

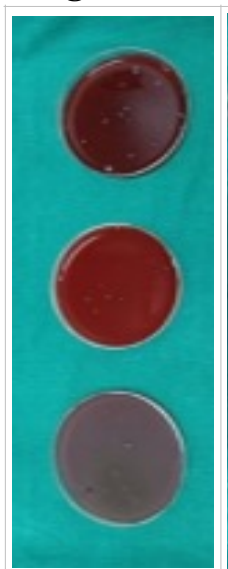

Neem

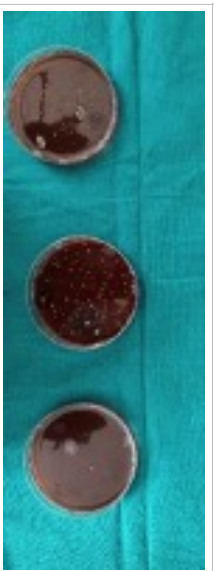

Triphala

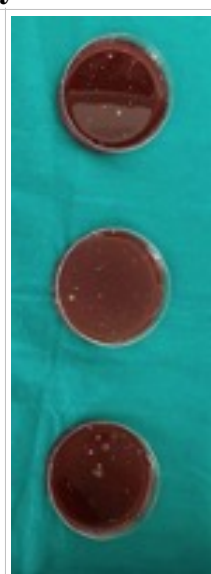

CHX

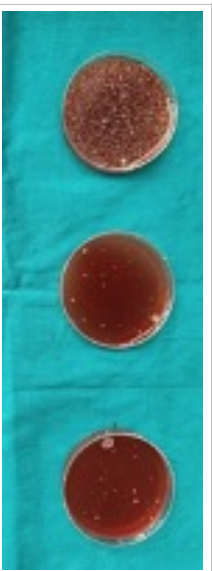

Water

\section{Statistical analysis}

Data was analyzed using Statistical Package for Social Sciences (SPSS) version 21, IBM Inc. Descriptive data was reported for each variable. Descriptive statistics such as mean and standard deviation for continuous variables was calculated.

Summarized data was presented using Tables and Graphs. Shapiro Wilk test was used to check the normality of the data. As the data was found to be normally distributed bivariate analyses was performed using One way ANOVA followed by tukey's for post hoc comparison. Level of statistical significance was set at $\mathrm{p}$-value less than 0.05 .

\section{Analysis of variance}

Analysis of variance (ANOVA) is used when we compare more than two groups simultaneously. The purpose of one-way ANOVA is to find out whether data from several groups have a common mean. That is, to determine whether the groups are actually different in the measured characteristic. One way ANOVA is a simple special case of the linear model. For more than 
two independent groups, simple parametric ANOVA is used when variables under consideration follows Continuous exercise group distribution and groups variances are homogeneous otherwise non parametric alternative Kruskal-Wallis $(\mathrm{H})$ ANOVA by ranks is used. The one way ANOVA form of the model is

where:

$$
Y_{i j}=\alpha_{. j}+\varepsilon_{i j}
$$

- $Y_{i j}$ is a matrix of observations in which each column represents a different group.

- $\alpha_{j}$ is a matrix whose columns are the group means (the "dot $\mathrm{j}$ " notation means that $\alpha$ applies to all rows of the $\mathrm{j}^{\text {th }}$ column i.e. the value $\alpha_{\mathrm{ij}}$ is the same for all $\mathrm{i}$ ).

- $\varepsilon_{i j}$ is a matrix of random disturbances.

The model posits that the columns of $\mathrm{Y}$ are a constant plus a random disturbance. We want to know if the constants are all the same.

\section{Assumptions are}

- Response variable must be normally distributed (or approximately normally distributed).

- Samples are independent.

- Variances of populations are equal.

- The sample is a simple random sample (SRS).

Two-way ANOVA is used when we have one measurement variable and two nominal variables, and each value of one nominal variable is found in combination with each value of the other nominal variable. It tests three null hypotheses: that the means of the measurement variable are equal for different values of the first nominal variable; that the means are equal for different values of the second nominal variable; and that there is no interaction (the effects of one nominal variable don't depend on the value of the other nominal variable). When we have a quantitative continuous outcome and two categorical explanatory variables, we may consider two kinds of relationship between two categorical variables, In this relationship we can distinguish effect of one factor from that of the other factor. This type of model is called a main effect model or no interaction model.

\section{Tukey Multiple Comparison Test}

After performing ANOVA, Tukey HSD (honestly significant difference) post hoc test is generally used to calculate differences between group means as

$$
\mathrm{q}=\frac{\overline{\mathrm{X}}_{1}-\overline{\mathrm{X}}_{2}}{\mathrm{SE}} \quad \mathrm{SE}=\sqrt{\frac{\mathrm{S}^{2}}{2}\left(\frac{1}{\mathrm{n}_{1}}+\frac{1}{\mathrm{n}_{2}}\right)}
$$

$\mathrm{S}^{2}$ is the error mean square from the analysis of variance and $n_{1}$ and $n_{2}$ are number of data in group 1 and 2 respectively.

\section{Statistical significance}

Level of significance "p" is level of significance signifies as below:
$\mathrm{p}>0.05$
Not significant (ns)
$\mathrm{p} \leq 0.05$

\section{Results}

\begin{tabular}{|c|c|c|c|c|c|c|c|c|}
\hline & \multirow[t]{2}{*}{$\mathbf{N}$} & \multirow[t]{2}{*}{ Mean } & \multirow{2}{*}{$\begin{array}{l}\text { Std. } \\
\text { Deviation }\end{array}$} & \multirow[t]{2}{*}{ Std. Error } & \multicolumn{2}{|c|}{$\begin{array}{l}\text { 95\% Confidence Interval for } \\
\text { Mean }\end{array}$} & \multirow[t]{2}{*}{ Minimum } & \multirow[t]{2}{*}{ Maximum } \\
\hline & & & & & Lower Bound & Upper Bound & & \\
\hline Group A- Neem & 5 & 9.800 & 5.8052 & 2.5962 & 2.592 & 17.008 & 1.0 & 15.0 \\
\hline Group B-Chx & 5 & 25.400 & 26.3591 & 11.7881 & -7.329 & 58.129 & 4.0 & 70.0 \\
\hline Group C-Triphala & 5 & 73.200 & 80.4189 & 35.9644 & -26.653 & 173.053 & 4.0 & 200.0 \\
\hline Group D-Water & 5 & 95.000 & 75.8288 & 33.9116 & 0.846 & 189.154 & 25.0 & 200.0 \\
\hline
\end{tabular}

Table 1 :Intergroup comparison of bioaerosol production by counting colony forming units in spitoon

$P$ value

0.100

Table 1- Intergroup comparison of bioaerosol production by counting colony forming units in spittoon. Though colony count was found to be maximum in Group D and least in Group A followed by Group B and C, but this difference failed to reach the level of statistical significance as $p>0.05$.

\begin{tabular}{|c|c|c|c|c|c|c|c|c|}
\hline & \multirow[t]{2}{*}{$\mathbf{N}$} & \multirow[t]{2}{*}{ Mean } & \multirow{2}{*}{$\begin{array}{c}\text { Std. } \\
\text { Deviation }\end{array}$} & \multirow[t]{2}{*}{ Std. Error } & \multicolumn{2}{|c|}{$\begin{array}{l}\text { 95\% Confidence Interval for } \\
\text { Mean }\end{array}$} & \multirow[t]{2}{*}{ Minimum } & \multirow[t]{2}{*}{ Maximum } \\
\hline & & & & & Lower Bound & Upper Bound & & \\
\hline Group A-Neem & 5 & 75.000 & 45.5522 & 20.3715 & 18.440 & 131.560 & 30.0 & 150.0 \\
\hline Group B-CHX & 5 & 84.000 & 14.7479 & 6.5955 & 65.688 & 102.312 & 70.0 & 100.0 \\
\hline Group C-Triphala & 5 & 90.000 & 22.3607 & 10.0000 & 62.236 & 117.764 & 50.0 & 100.0 \\
\hline Group D-Water & 5 & 166.000 & 47.7493 & 21.3542 & 106.711 & 225.289 & 100.0 & 200.0 \\
\hline$P$ value & \multicolumn{8}{|c|}{0.003} \\
\hline Post hoc & \multicolumn{8}{|c|}{$4>3>2>1$} \\
\hline
\end{tabular}

Table 2 -Intergroup comparison of bioaerosol production by counting colony forming units on chest

Overall significant difference was seen in the mean colony count when compared using one way ANOVA test as $\mathrm{p}<0.05$. Post hoc comparison using Tukey's test showed significantly lesser colony count followed by CHX, Triphala and water group. 
International Journal of Ayurvedic Medicine, Vol 12 (3), 593-598

Table 3 - Intergroup comparison of bioaerosol production by counting colony forming units on tray

\begin{tabular}{|c|c|c|c|c|c|c|c|c|} 
& N & Mean & $\begin{array}{c}\text { Std. } \\
\text { Deviation }\end{array}$ & $\begin{array}{c}\text { Std. } \\
\text { Error }\end{array}$ & $\begin{array}{c}\mathbf{9 5 \%} \text { Confidence Interval for Mean } \\
\text { Lower Bound }\end{array}$ & Upper Bound & Minimum & Maximum \\
\hline Group A-Neem & 5 & 7.200 & 4.2778 & 1.9131 & 4.288 & 14.912 & 4.0 & 15.0 \\
\hline Group B-CHX & 5 & 9.600 & 3.7014 & 1.6553 & 2.604 & 11.796 & 3.0 & 12.0 \\
\hline Group C-Triphala & 5 & 42.200 & 60.8498 & 27.2129 & -33.355 & 117.755 & 5.0 & 150.0 \\
\hline Group D-Water & 5 & 56.400 & 80.2795 & 35.9021 & -43.280 & 156.080 & 20.0 & 200.0 \\
\hline P value & & & & & 0.354 & & &
\end{tabular}

Table 3 -States that the Intergroup comparison of bioaerosol production by counting colony forming units on tray. Though colony count was found to be maximum in Group D and least in Group A followed by Group B and C, but this difference failed to reach the level of statistical significance as $p>0.05$.
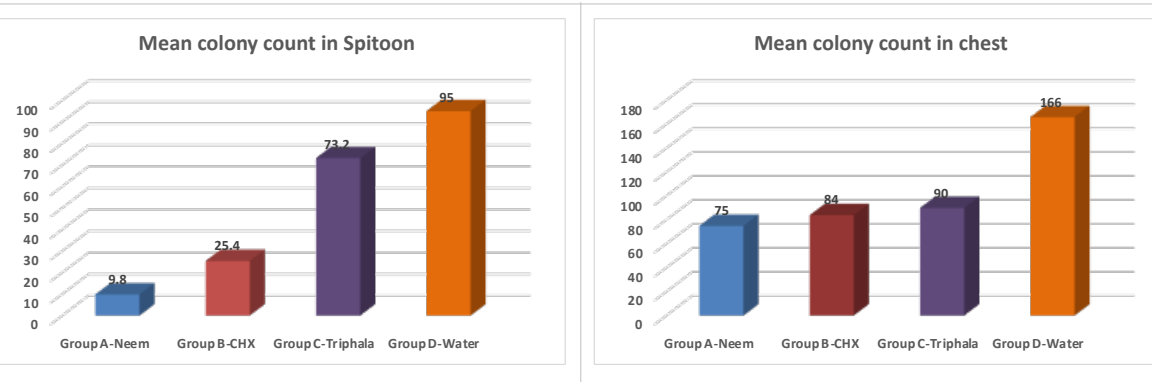

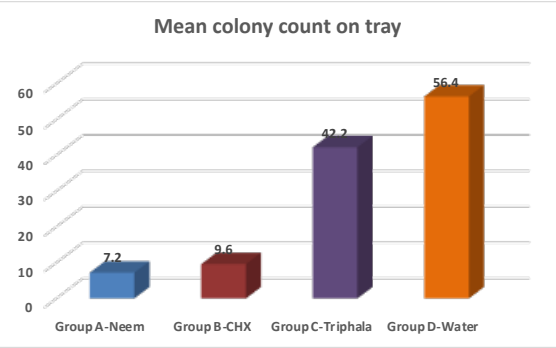

\section{Discussion}

The generated aerosol while performing a dental procedure in concurrence with bacterial infection can cause a potential hazard to the dentist as well as to the patients. This study has confirmed that aerosol and splatter are produced in significant amounts by the ultrasonic scaler device in the arena of dentistry. There is a potential threat for infection to spread owing to the aerosols produced. This demands the use of mouth rinses before the procedure to possess slight bacterial load.(5)

In a study conducted by Fine et al, (11) it was shown that pre-procedural oral rinsing with an antiseptic mouthwash considerably decreased the viable microbial content of bio-aerosols produced during dental trials. It was recommended that this preprocedural rinsing may have a significant part in reducing the risk of cross contamination with infectious agents in the dental operatory. Gunjan gupta et al (12) compared the efficacy of $0.2 \%$ chlorhexidine, and herbal mouth wash(Test Groups) to water (Control group) and found that both the test groups reduced CFUs significantly when compared to the control group. They concluded that chloxhexidine group was superior to herbal mouth wash group. But in a study done by Koduganti Rekha Rani there were no statistical difference between the test groups i.e., chlorhexidine and herbal mouth rinse (13)

In the present study, the effectiveness of preprocedural rinsing with herbal rinse was compared with $0.2 \%$ Chlorhexidine which was considered as a gold standard. The outcomes of this study revealed that 10 $\mathrm{ml}$ of Neem Mouth rinse when used 10 minutes prior to ultrasonic scaling is more effective in decreasing the aerosol infection as compared to the Triphala mouth rinse and commercially available $0.2 \%$ Chlorhexidine mouthrinse. And also the decrease in aerosol content was seen in Tray location when rinsed with CHX and aerosol reduction in Spitoon and Chest location while rinsing with Neem mouthrinse. Also the patient's chest location was more exposed to the microbial aerosols as compared to the tray location and spitoon location which demands the usage of preventive methods to lessen cross contamination in a dental practice.

Even though the discovery of chlorhexidine was done in the early 1950s, it is still well thought-out as the most effective antiplaque agent in dentistry. However, because of its displeasing taste and proclivity to stain the teeth brown, its use is limited. As the taste should not be a hindrance for its use with maximal inhibition of bacteria and plaque, $2 \%$ of neem was used in this study. For reducing periodontal that registers as chlorhexidine, neem mouthwash was very effective. When compared with $0.2 \%$ chlorhexidine gluconate mouthwash, neem mouthwash is considered to be costeffective. Hence, the neem extract can be used as a healthier substitute mouthwash to $0.2 \%$ chlorhexidine gluconate mouthwash in low socioeconomic status population. Chlorhexidine mouthwash revealed a greater effect on the reformation of plaque and inflammation of gingiva when compared with that by neem mouthwash.(14)

Though aerosol production cannot be completely eradicated with infection control procedures, the putative potential of these aerosols can be minimised by preprocedural rinsing. Pre-rinsing with herbal mouth rinse was more effective than chlorhexdine in this study which promotes the use of herbal rinses in the dental setting.(13)

\section{Conclusion}

The study suggests that $10 \mathrm{ml}$ of Neem Mouth rinse when used 10 minutes prior to ultrasonic scaling is more potent in reducing the aerosol contamination as compared to the Triphala mouth rinse and commercially available $0.2 \%$ Chlorhexidine mouthrinse. And also the 
Chinnu Mary Varghese et.al., Herbal Mouth Rinse as an alternative to Chemical Mouth Rinse in Reducing Dental Aerosols

reduction in aerosol content was seen in Tray location when rinsed with $\mathrm{CHX}$ and aerosol reduction in Spitoon and Chest location while rinsing with Neem mouthrinse.

It can be concluded as: Neem $>$ Chlorhexidine $>$ Triphala $>$ Water

Also the patient's chest location was more exposed to the microbial aerosols as compared to the tray location and spitoon location which necessitates the usage of preventive methods to reduce cross contamination in a dental practice.

\section{References}

1. Yadav S, Kumar S, Srivastava P, Gupta KK, Gupta J, Khan YS. Comparison of efficacy of three different mouthwashes in reducing aerosol contamination produced by ultrasonic scaler: A pilot study. Indian Journal of Dental Sciences. 2018 Jan $1 ; 10(1) ; 6-10$

2. Samaranayake LP, Anil S, Scully C. Occupational Hazards in Dentistry: Part I. F D I World. International Journal of Experimental Dental Science · January 2013;2(1):33-40.

3. Szymanska J. Dental bioaerosol as an occupational hazard in a dentist's workplace. Annals of Agricultural and Environmental Medicine.2007;14(2).203-207.

4. Abichandani S, Nadiger R. Cross contamination in dentistry: A comprehensive overview. Journal of Education and Ethics in Dentistry. 2012 Jan $1 ; 2(1) ; 3-9$

5. Mani SS, Srikanthan S, Selvaraj B, Menaka V, Diwakar MK. Effectiveness of $0.2 \%$ chlorhex plus and $0.1 \%$ turmix as preprocedural mouth rinses on aerosol contamination produced by ultrasonic scalers: An interventional study. Journal of Dental Research and Review. 2020 Jan 1;7(1):5-9

6. Harrel SK, Molinari J. Aerosols and splatter in dentistry: a brief review of the literature and infection control implications. The Journal of the American Dental Association. 2004 Apr $1 ; 135(4) ; 429-437$.

7. Lyle D. The role of pharmacotherapeutics in the reduction of plaque and gingivitis. J Prac Hyg. 2000; 5 :46-50.

8. Santos A. Evidence-based control of plaque and gingivitis. Journal of clinical periodontology 2003 Jun;30;13-6.

9. Gupta G, Mitra D, Ashok KP, Gupta A, Soni S, Ahmed S, Arya A. Efficacy of preprocedural mouth rinsing in reducing aerosol contamination produced by ultrasonic scaler: a pilot study. Journal of periodontology. 2014 Apr;85(4);562-568.

10. Prakash S, Shelke AU. Role of Triphala in dentistry. Journal of Indian Society of Periodontology. 2014 Mar;18(2);132-135.

11. Fine DH, Mendieta C, Barnett ML, Furgang D, Meyers R, Olshan A, et al. Efficacy of preprocedural rinsing with an antiseptic in reducing viable bacteria in dental clinic. J Periodontol 1992;63;821-4.

12. Gupta G, Mitra D, Ashok KP, Gupta A, Soni S, Ahmed S, Arya A. Efficacy of preprocedural mouth rinsing in reducing aerosol contamination produced by ultrasonic scaler: a pilot study. Journal of periodontology. 2014 Apr;85(4);562-568.

13. Rani KR, Ambati M, Prasanna JS, Pinnamaneni I, Reddy PV, Rajashree D. Chemical vs. herbal formulations as pre-procedural mouth rinses to combat aerosol production: A randomized controlled study. Journal of Oral Research and Review. 2014 Jan 1;6(1);9-13.

14. Jalaluddin M, Rajasekaran UB, Paul S, Dhanya RS, Sudeep CB, Adarsh VJ. Comparative Evaluation of Neem Mouthwash on Plaque and Gingivitis: A Double-blind Crossover Study. The journal of contemporary dental practice. 2017 Jul $1 ; 18(7) ; 567-571$. 